\title{
Production of cellulases and xylanase by Aspergillus fumigatus SK1 using untreated oil palm trunk through solid state fermentation
}

\begin{abstract}
Direct utilization of untreated oil palm trunk (OPT) for cellulases and xylanase production by Aspergillus fumigatus SK1 was conducted under solid-state fermentation (SSF). The highest activities of extracellular cellulases and xylanases were produced at $80 \%$ moisture level, initial pH 5.0, $1 \times 108$ spore/g (inoculum) with $125 \mathrm{\varepsilon m}$ of OPT as sole carbon source. The cellulases and xylanase activities obtained were 54.27, 3.36, 4.54 and $418.70 \mathrm{U} / \mathrm{g}$ substrates for endoglucanase (CMCase), exoglucanase (FPase), b-glucosidase and xylanase respectively. The crude cellulases and xylanase required acidic condition to retain their optimum activities ( $\mathrm{pH} 4.0)$. Crude cellulases and xylanase were more stable at $40^{\circ} \mathrm{C}$ compared to their optimum activities conditions $\left(60^{\circ} \mathrm{C}\right.$ for FPase and $70^{\circ} \mathrm{C}$ for CMCase, $\mathrm{b}$ glucosidase and xylanase). SDS-PAGE and zymogram analysis showed that Aspergillus fumigatus SK1 could secrete cellulases (endoglucanase, exoglucanase and b-glucosidase), xylanase and protease. Enzymatic degradation of alkaline treated OPT with concentrated crude cellulases and xylanases resulted in producing polyoses.
\end{abstract}

Keyword: Oil palm trunk (OPT); Cellulases; Xylanase; Solid-state fermentation; Saccharification 